\title{
Evolving arch surgery using integrated antegrade selective cerebral perfusion: Impact of axillary artery perfusion
}

Hitoshi Ogino, MD, ${ }^{a}$ Hiroaki Sasaki, MD, ${ }^{a}$ Kenji Minatoya, MD, ${ }^{a}$ Hitoshi Matsuda, MD, ${ }^{a}$ Hiroshi Tanaka, MD, ${ }^{a}$ Hirotaka Watanuki, MD, ${ }^{a}$ Motomi Ando, MD, ${ }^{\mathrm{b}}$ and Soichiro Kitamura, MD ${ }^{\mathrm{a}}$

From the Department of Cardiovascular Surgery, National Cardiovascular Center, ${ }^{\mathrm{a}}$ and Department of Thoracic Surgery, Fujita Health University, ${ }^{\mathrm{b}}$ Aichi, Japan.

Received for publication Oct 17, 2007; revisions received Dec 21, 2007; accepted for publication Feb 19, 2008.

Address for reprints: Hitoshi Ogino, MD, Department of Cardiovascular Surgery, National Cardiovascular Center, 5-7-1 Fujishirodai, Suita, Osaka, 565-8565, Japan (E-mail: hogino@hsp.ncvc.go.jp).

J Thorac Cardiovasc Surg 2008;136:641-9 $0022-5223 / \$ 34.00$

Copyright (C) 2008 by The American Association for Thoracic Surgery

doi:10.1016/j.jtcvs.2008.02.089
Objective: The study objective was to determine the impact of integrated antegrade selective cerebral perfusion with right axillary artery perfusion during arch surgery.

Methods: All surgeries were performed through a median sternotomy. Direct cannulation of the right axillary artery in the axilla was used for cardiopulmonary bypass and antegrade selective cerebral perfusion under hypothermia. In addition, ascending aortic or femoral artery perfusion was used. The clinical records of 531 patients (median age, 72 years) between 1999 and 2006 were reviewed, of whom 137 patients $(25.8 \%)$ underwent emergency surgery. There were 164 dissecting and 367 nondissecting aortic lesions. The surgeries included total arch replacement in 431 patients, partial arch replacement in 9 patients, and hemiarch replacement in 91 patients.

Results: The early mortality rate was $4.0 \%$ (2.3\% of 30-day mortality and $1.7 \%$ of inhospital mortality). The incidence of permanent neurologic dysfunction was $2.9 \%$ in all (3.3\% in total arch replacement and $1.0 \%$ in hemiarch or partial arch replacement). The incidence of temporary dysfunction was $9.9 \%$ in all (10.6\% in total arch replacement and $7.0 \%$ in hemiarch or partial arch replacement). Multivariate analysis demonstrated that the risk factors for early mortality were chronic renal failure, ruptured nondissecting aneurysm, and prolonged surgery. The midterm survival was $87.2 \% \pm 1.7 \%$ at 3 years and $80.5 \% \pm 2.6 \%$ at 5 years.

Conclusion: Right axillary artery perfusion is an advantageous adjunct to cardiopulmonary bypass and antegrade selective cerebral perfusion in arch surgery.

$\mathrm{S}$ urgery for various aortic arch pathologies, including acute aortic dissection or ruptured atherosclerotic aneurysms, still features high mortality and morbidity. ${ }^{1-5}$ In particular, postoperative cerebral morbidities remain prevalent despite recent great advances in intraoperative brain protection. ${ }^{1-5} \mathrm{We}$ have routinely used antegrade selective cerebral perfusion (SCP) under right axillary artery (RAxA) perfusion in conjunction with deep or moderate hypothermia. ${ }^{6}$ The aim of this retrospective study is to determine the early and midterm outcome of arch surgery using integrated SCP with RAxA perfusion and to analyze relevant risk factors for early mortality and cerebral morbidity.

\section{Patients and Methods \\ Patients}

We reviewed the clinical records of 531 patients who underwent various aortic arch surgeries between 1999 and 2006 at the National Cardiovascular Center, Japan (Table 1). The median age was 72 years (19-89 years). Routine clinical history and physical examination, including evaluation of brain, coronary, and peripheral ischemia, were done preoperatively. Particularly in regard to cerebral ischemia, brain computed tomographic scanning and carotid ultrasound were routinely performed. With any positive findings, further magnetic resonance imaging/angiography and Diamox loading cerebral flow scintigraphy followed, together with consultation 


\section{Abbreviations and Acronyms}

$\mathrm{CPB}=$ cardiopulmonary bypass

RAxA = right axillary artery

$\mathrm{SCP}=$ selective cerebral perfusion

with neurophysicians or neurosurgeons. In 3 patients with carotid artery stenosis, carotid artery endarterectomy in 1 patient and carotid artery stenting in 2 patients were performed before the arch surgery. For coronary ischemia, dipyridamole loading Thallium perfusion scintigraphy was a routine examination in the early series. Positive signs warranted coronary angiography. Since 2004, coronary angiography has been a routine examination. When coronary artery disease was detected, simultaneous coronary artery bypass grafting was carried out in almost all of the patients, or percutaneous catheter intervention was performed for some limited patients by cardiologists. On an emergency basis, including acute dissection or ruptured nondissecting aneurysm, these complete examinations were not feasible.

\section{Surgical Techniques and Brain Protection}

Bilateral temporal arterial lines were placed to monitor cerebral perfusion pressure. All aneurysms were approached through a median sternotomy.

1. Cardiopulmonary bypass (CPB) establishment with RAxA perfusion: RAxA perfusion was routinely used to establish CPB and SCP. ${ }^{6}$ The RAxA was exposed quickly through a 5 to $7-\mathrm{cm}$ skin incision in the axilla (Figure 1). After full heparinization, a $10 \mathrm{~F}$ to $16 \mathrm{~F}$ straight thin-walled cannula (Medtronic, Minneapolis, Minn) was inserted into the RAxA, depending on the artery size. Empirically, even a $12 \mathrm{~F}$ cannula allowed a flow of up to $1.5 \mathrm{~L} / \mathrm{min}$. In addition, the ascending aorta or femoral artery was cannulated for a total CPB flow of 1 to $2 \mathrm{~L} / \mathrm{min}$ through the RAxA and 2.5 to $3.5 \mathrm{~L} / \mathrm{min}$ via the ascending aorta or femoral artery. In the early series, femoral perfusion was routinely chosen. However, from 2003 to 2006, ascending aortic perfusion was predominantly used, although femoral perfusion was still an alternative for patients with a severely atherosclerotic ascending aorta. With severely atheromatous changes in the descending aorta, femoral perfusion was used to flush out debris that dislodged during the distal anastomosis. Bicaval venous drainage with left ventricular venting was performed. For patients with acute dissection, with standard femoral cannulation, RAxA perfusion was used to avoid the collapse of the true channel caused by retrograde femoral perfusion. In 4 patients whose left subclavian or innominate artery was occluded, left axillary perfusion was also used. In addition to RAxA perfusion, the ascending aorta was used in 141 patients, the ascending aorta and femoral artery were used in 57 patients, and the femoral artery was used in 333 patients.

2. Brain protection using SCP with RAxA perfusion (Figure 2, $A$ ): Alpha-stat management was used during hypothermia. We routinely used SCP combined with RAxA perfusion for brain protection. ${ }^{6,7}$ Immediately after the induction of hypothermic circulatory arrest by discontinuation of the as-
TABLE 1. Patient profile $(n=531)$

\begin{tabular}{|c|c|c|}
\hline Variable & No & $\%$ \\
\hline \multicolumn{3}{|l|}{ Gender } \\
\hline Male & 363 & 68.4 \\
\hline Female & 168 & 31.6 \\
\hline \multicolumn{3}{|l|}{ Aortic pathology } \\
\hline Dissecting & 164 & 30.9 \\
\hline Nondissecting (+ dissecting) & $367(39)$ & 69.1 \\
\hline \multicolumn{3}{|l|}{ Cause } \\
\hline Atherosclerosis & 357 & 67.2 \\
\hline Dissection & 151 & 28.4 \\
\hline Marfan syndrome & 11 & 2.1 \\
\hline Aortitis & 9 & 1.7 \\
\hline Infection & 2 & 0.4 \\
\hline \multicolumn{3}{|l|}{ Urgency } \\
\hline Elective & 394 & 74.2 \\
\hline Emergency & 137 & 25.8 \\
\hline Acute dissection & 108 & 20.3 \\
\hline Ruptured nondissecting & 21 & 4.0 \\
\hline Others ${ }^{\mathrm{a}}$ & 8 & 1.5 \\
\hline Reoperation & 42 & 7.9 \\
\hline \multicolumn{3}{|l|}{ Cerebrovascular disease } \\
\hline History of cerebrovascular accident & 120 & 22.6 \\
\hline Carotid disease & 54 & 10.2 \\
\hline Intracranial artery disease & 52 & 9.8 \\
\hline \multicolumn{3}{|l|}{ Coexisting disease } \\
\hline Coronary artery disease & 145 & 27.3 \\
\hline Chronic renal failure & 53 & 10.0 \\
\hline Chronic obstructive pulmonary disease & 99 & 4.0 \\
\hline Smoking & 267 & 50.2 \\
\hline Diabetes mellitus & 71 & 13.4 \\
\hline \multicolumn{3}{|l|}{ Lowest core temperature } \\
\hline Deep hypothermia $\left(20^{\circ} \mathrm{C}-22^{\circ} \mathrm{C}\right)$ & 232 & 43.7 \\
\hline Moderate hypothermia $\left(25^{\circ} \mathrm{C}-28^{\circ} \mathrm{C}\right)$ & 299 & 56.3 \\
\hline
\end{tabular}

aOthers: unstable aneurysm (eg, symptomatic nondissecting aneurysm, infected aneurysm).

cending or femoral perfusion, SCP with the constant flow through RAxA perfusion was easily commenced by clamping the innominate artery. The left common carotid and left subclavian arteries were also clamped. By means of this simple maneuver, sufficient perfusion of the right hemisphere with partial circulation of the left hemisphere through collateral vessels was quickly established. The ascending aorta was usually clamped, and cardioplegic solution was antegradely or retrogradely infused to attain cardiac arrest.

In the early series, the lowest bladder and nasopharyngeal temperatures were $20^{\circ} \mathrm{C}$ to $22^{\circ} \mathrm{C}$. Both temperatures have been increased in stages up to the current lowest temperature of $28^{\circ} \mathrm{C}$, except for high-risk patients with carotid or intracranial artery disease, or for patients with renal failure. For these patients, deep hypothermia was still used. The lowest temperature was $20^{\circ} \mathrm{C}$ in 151 patients, $22^{\circ} \mathrm{C}$ in 81 patients, $25^{\circ} \mathrm{C}$ in 141 patients, and $28^{\circ} \mathrm{C}$ in 158 patients.

3. Total arch replacement (Figure 2,B): The ascending aorta and transverse arch were opened, and a $12 \mathrm{~F}$ or $14 \mathrm{~F} \mathrm{SCP}$ 

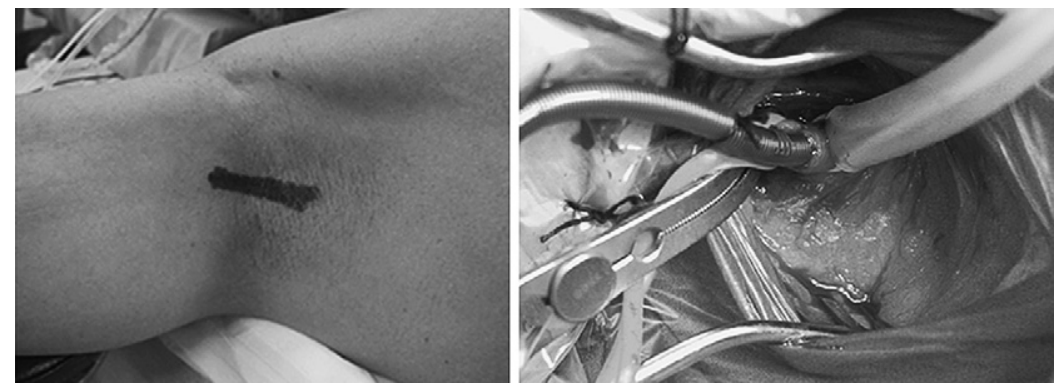

Figure 1. RAxA perfusion in the axilla. The distal part of the RAxA was exposed through a 5- to 7-cm skin incision in the axilla. A $10 \mathrm{~F}$ to $16 \mathrm{~F}$ straight thin-walled cannula was inserted depending on the size of the artery.

balloon-tipped cannula was inserted from within the aorta into the left common carotid artery. Between 1999 and 2002, SCP was instituted by RAxA and left common carotid artery perfusion, with the left subclavian artery clamped, at $20^{\circ} \mathrm{C}$ to $22^{\circ} \mathrm{C}$. During SCP, the pressures of the bilateral superficial temporal artery or the balloon tips were maintained in the range of 30 to $50 \mathrm{~mm} \mathrm{Hg}$. Subsequently, SCP flows of 10 to $12 \mathrm{~mL} / \mathrm{kg} / \mathrm{min}$ were generated by a single roller pump separate from the systemic circulation. In 2003, left subclavian perfusion using another balloon-tip cannula was added, and the lowest temperature has been gradually increased from $25^{\circ} \mathrm{C}$ to $28^{\circ} \mathrm{C}$. At $28^{\circ} \mathrm{C}$, the $\mathrm{SCP}$ flow was also increased up to approximately $15 \mathrm{~mL} / \mathrm{kg} / \mathrm{min}$ to maintain perfusion pressure between 50 and $70 \mathrm{~mm} \mathrm{Hg}$. Through the aneurysm, the descending aorta distal to the aneurysm was transected from the inside using an electrical cautery, avoiding nerve and lung injury. Open distal anastomosis was performed during hypothermic circulatory arrest of the lower half body. "Stepwise distal anastomosis," with a shortlength tube graft interposition, was frequently used for an easy and secure anastomosis. The details have been described. ${ }^{6,7}$ An invaginated tube graft of 7 to $12 \mathrm{~cm}$ in length, composed of the multibranched Dacron graft, was inserted into the descending aorta. The proximal end was anastomosed to the descending aorta. The distal end of the inserted graft was then extracted proximally. The multibranched arch graft was connected to this interposed graft. Systemic circulation was resumed using a branch graft. The left subclavian artery was reconstructed, and the patient was rewarmed to $30^{\circ} \mathrm{C}$ to $32^{\circ} \mathrm{C}$ with an SCP flow of 1 to $1.5 \mathrm{~L} / \mathrm{min}$ and a branch graft flow of 3 to $4 \mathrm{~L} / \mathrm{min}$. Then, the proximal aortic anastomosis above the sinotubular junction was made. Coronary circulation was initiated by unclamping. The other arch vessels were reconstructed, and the patient was fully rewarmed with a slightly higher total flow of 4 to $6 \mathrm{~L} / \mathrm{min}$. In patients with a risk of cerebral morbidity because of carotid or intracranial artery lesions, arch-vessel reconstruction was preferentially performed before the proximal aortic anastomosis. For 26 patients with extensive aneurysm involving the arch, 2-stage surgery was performed with stage I total arch replacement with an elephant trunk procedure. It was followed by stage II descending aortic replacement in 12 patients and by endoluminal stent grafting in 6 older patients with respiratory dysfunction.

4. Hemiarch or partial arch replacement: The proximal arch was beveled proximal to the innominate artery. SCP balloon-tipped cannulae were inserted from within the aorta into the left common carotid artery with or without the left subclavian artery perfusion. A 22 to $26-\mathrm{mm}$ single-branched Dacron graft was anastomosed with an open aortic technique. Distal perfusion was commenced using a branchgraft, and the patient was rewarmed. Then, the proximal anastomosis was made. In case of partial arch replacement, the innominate artery was reconstructed using an 8 to 10-mm branch graft.

5. Acute type A dissection: Hemiarch repair was the procedure principally used for our tear-oriented surgery. The false channel was closed with inside-outside Teflon felt strips. Extended total arch replacement was attempted in the following settings: 1) tear in the arch or proximal descending aorta, 2) Marfan syndrome, 3) arch aneurysm or dilatation, 4) atheromatous arch, 5) massive arch dissection, and 6) relatively

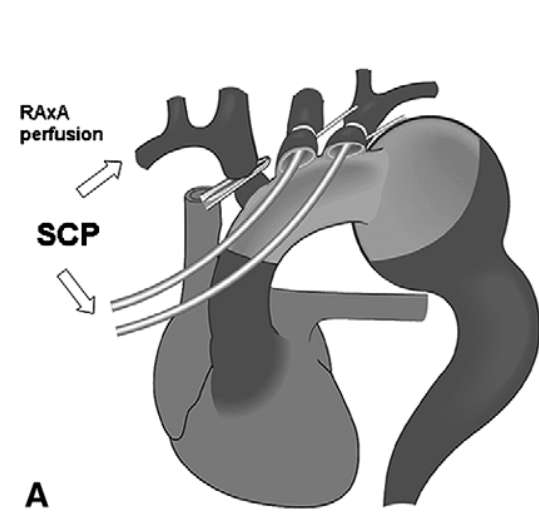

B

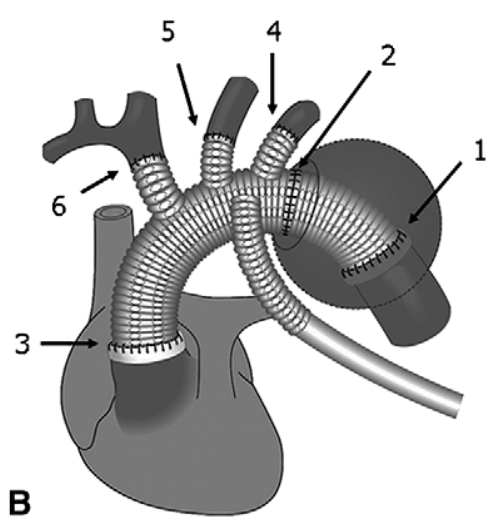

Figure 2. Total arch replacement using SCP with RAxA perfusion. A, Antegrade SCP with the perfusion through the RAxA, left common carotid artery, and left subclavian artery. B, Total arch replacement with a stepwise distal anastomosis using a multibranched Dacron graft. The numbers 1 to 6 show the turn of anastomosis. RAxA, Right axillary artery; $S C P$, selective cerebral perfusion. 
young age ( $<70$ years). The descending aorta was transected distal to the left subclavian artery. A modified elephant trunk technique was used for a secure anastomosis and early thrombosed closure of the distal false channel. A prosthetic graft of 16 to $24 \mathrm{~mm}$ in diameter was inserted into the distal true channel. The proximal end was attached to the descending aorta with the reinforcement with an external Teflon felt strip. Another multibranched arch graft was anastomosed to this aortic stump. Antegrade distal aortic perfusion was commenced with a branch graft. The left subclavian artery was reconstructed. At the proximal site, the ascending aorta was transected just around the sinotubular junction. The proximal false channel was closed with internal and external Teflon felt strips. In most, the proximal false channel was fixed using Gelatin-Resorcin-Formal glue (Cardial, SainteEtienne, France). The main graft was anastomosed to this end. Finally, the other arch vessels were reconstructed using branch grafts under SCP.

Arch repairs included total arch replacement in 431 patients, partial arch in 9 patients, and hemiarch in 91 patients. Concomitantly, coronary artery bypass $(n=95)$, composite root repair $(n=21)$, valve-sparing surgery $(\mathrm{n}=6)$, sinotubular junction plication $(\mathrm{n}=$ $27)$, aortic valve replacement $(n=29)$, mitral valve repair $(n=$ $3)$ /replacement $(n=3)$, tricuspid annuloplasty $(n=6)$, atrial septal defect closure $(\mathrm{n}=1)$, arch-vessel reconstruction for the anomaly (n $=9)$, and peripheral bypass $(n=2)$ were performed. At the end, the cannula was removed from the RAxA, and the cannulation site was closed using a 6-0 polypropylene suture.

\section{Definition of Neurologic Deficits and Other Variables}

Permanent neurologic dysfunction was defined as the presence of permanent deficits persisting at discharge. Transient dysfunction was defined as the occurrence of confusion, agitation, obtundation, or delay of full awakening. It was difficult to distinguish between transient neurologic dysfunction and frequently occurring delirium in the elderly. When delirium was severe, it was also included in transient neurologic dysfunction. Cerebrovascular event included old cerebral infarction (including asymptomatic one) in 116 patients and cerebral hemorrhage in 4 patients. Carotid artery disease was defined as the presence of more than $50 \%$ stenosis or multiple plaques on ultrasound examination. Intracranial artery disease was defined as more than $75 \%$ stenosis of intracranial vessels on magnetic resonance angiography or as hypoperfusion on Diamox loading cerebral flow scintigraphy. Chronic renal failure was defined as a serum creatinine level of more than $1.5 \mathrm{mg} / \mathrm{dL}$ or the requirement of hemodialysis. Chronic obstructive pulmonary disease was defined as forced expiratory volume in 1 second less than $70 \%$ of the normal value. Reoperation was defined as re-sternotomy surgery after cardiac or aortic root to arch surgery. The patients who had previously undergone proximal descending replacement through left thoracotomy were also included among the reoperation cases, because it was sometimes troublesome to make the distal anastomosis to the prosthetic graft of the previous proximal descending aortic replacement.

\section{Data Collection and Statistical Analysis}

All of the surgeries were identified from the Registry of Cardiovascular Surgery in the National Cardiovascular Center. The data in the registry were approved for use by the institutional ethical commit- tee. The follow-up rate was $99.6 \%(529 / 531)$, because 2 patients who underwent total arch replacement were lost to follow-up. The mean follow-up period was $2.7 \pm 1.8$ years. We retrospectively reviewed the overall outcome and investigated the risk factors for early mortality, including 30-day and in-hospital mortality, and permanent neurologic dysfunction. Statistical analysis was carried out using StatView 5.0 (SAS Institute, Cary, NC) software. Values were expressed as the mean \pm standard deviation or medians (range). Univariate and multivariate logistic regression analyses were used to investigate risk factors for early mortality and permanent neurologic dysfunction. According to clinical importance and the result of univariate analysis, advanced age, ruptured nondissecting aneurysm, coronary artery disease, chronic renal failure, diabetic mellitus, concomitant surgery, prolonged surgery, and deep hypothermia $\left(20^{\circ} \mathrm{C}-22^{\circ} \mathrm{C}\right)$ were involved in the following multivariate analysis for early mortality. For permanent neurologic dysfunction, multivariate analysis was not performed because of a low event rate and strong association of atheromatous ascending aorta and arch. Kaplan-Meier estimate was used to calculate the survival.

\section{Results}

The hypothermic circulatory arrest for open distal anastomosis, myocardial ischemia, SCP, CPB, and surgery lasted 57.0 \pm 19.9 minutes, $129.7 \pm 45.8$ minutes, $134.6 \pm 62.3$ minutes, $233.3 \pm 106.3$ minutes, and $483.3 \pm 189.7$ minutes, respectively. The early mortality rate was $4.0 \%(21 / 531)$. Within 30 days, 12 patients $(2.3 \%)$ died: acute dissection in 3 patients $(2.7 \%)$, chronic dissection in 1 patient $(1.9 \%)$, nonruptured nondissecting aneurysm in 6 patients $(1.8 \%)$, and ruptured nondissecting in 2 patients $(2.7 \%)$. The in-hospital mortality was $1.7 \%$ (9/519): acute dissection in 1 patient $(0.9 \%)$ and nonruptured nondissecting aneurysm in 8 patients $(2.4 \%)$. Table 2 shows the result of univariate and multivariate analyses of risk factors for early mortality. The multivariate analysis demonstrated that the risk factors for early mortality were chronic renal failure, ruptured nondissecting aneurysm, and prolonged surgery.

The presence of cerebral complications could not be assessed in 8 patients who died immediately after the surgery without awakening. The incidence of permanent neurologic dysfunction was $2.9 \%$ (15/523): acute dissection in 4 patients $(3.6 \%)$, chronic dissection in 1 patient $(1.9 \%)$, nonruptured nondissecting in 7 patients $(2.1 \%)$, and ruptured nondissecting in 3 patients $(12.0 \%)$. Permanent neurologic dysfunction developed in $3.3 \%$ of patients (14/423) with total arch replacement and $1.0 \%$ of patients (1/100) with hemiarch or partial arch replacement. The incidence of temporary dysfunction was $9.9 \%$ (52/523): acute dissection in 10 patients $(9.1 \%)$, chronic dissection in 3 patients $(5.7 \%)$, and nonruptured nondissecting aneurysm in 39 patients (11.6\%). Temporary dysfunction developed in 10.6\% (45/ $423)$ with total arch replacement and 7\% (7/100) with hemiarch or partial arch replacement. Univariate analysis demonstrated that the risk factors for permanent dysfunction were atheromatous ascending aorta and arch, arch-vessel 
TABLE 2. Risk factors for early mortality determined by univariate and multivariate analyses

\begin{tabular}{|c|c|c|c|c|}
\hline \multirow[b]{2}{*}{ Variable } & \multicolumn{2}{|c|}{ Univariate } & \multicolumn{2}{|c|}{ Multivariate } \\
\hline & $\boldsymbol{P}$ & OR (95\% Cl) & $\boldsymbol{P}$ & OR (95\% Cl) \\
\hline Age (y) & .090 & $1.05(0.99-1.11)$ & .096 & $1.06(0.99-1.13)$ \\
\hline Male gender & .434 & $1.50(0.54-4.17)$ & & \\
\hline Dissecting aneurysm & .476 & $0.69(0.25-1.92)$ & & \\
\hline Emergency surgery & .767 & $1.16(0.44-3.05)$ & & \\
\hline Acute dissection & .881 & $0.92(0.30-2.79)$ & & \\
\hline Ruptured nondissecting aneurysm & .023 & $4.56(1.23-16.89)$ & .049 & $4.70(1.00-22.03)$ \\
\hline Acute dissection with critical malperfusion & .052 & $4.78(0.99-23.07)$ & & \\
\hline Reoperation & .065 & $2.92(0.94-9.12)$ & & \\
\hline Marfan syndrome & .393 & $2.50(0.31-20.49)$ & & \\
\hline Chronic renal failure & .001 & $5.04(1.94-13.13)$ & .007 & $4.82(1.54-15.05)$ \\
\hline Chronic obstructive pulmonary disease & .085 & $2.27(0.89-5.79)$ & & \\
\hline Coronary artery disease & .001 & $4.65(1.89-11.48)$ & .170 & $2.16(0.72-6.46)$ \\
\hline Diabetes mellitus & .010 & $3.48(1.36-8.96)$ & .314 & $1.77(0.58-5.41)$ \\
\hline Concomitant surgery & .009 & $3.26(1.35-7.90)$ & .843 & $1.12(0.36-3.49)$ \\
\hline Surgery (h) & $<.0001$ & $1.24(1.14-1.36)$ & $<.0001$ & $1.31(1.16-1.48)$ \\
\hline Deep hypothermia $\left(20^{\circ} \mathrm{C}-22^{\circ} \mathrm{C}\right)$ & .013 & $3.38(1.29-8.84)$ & .228 & $1.93(0.66-5.65)$ \\
\hline
\end{tabular}

$O R$, Odds ratio; $\mathrm{Cl}$, confidence interval.

malperfusion caused by acute dissection, chronic renal failure, and female gender (Table 3).

After surgery, various complications developed: bleeding in $7.5 \%(n=40)$, low cardiac output in $6.2 \%(33)$, respiratory failure requiring tracheotomy or prolonged ventilation for 3 days in $14.1 \%$ (75), acute renal failure requiring hemodialysis in $2.3 \%$ (12), hepatic failure in $0.8 \%$ (4), gastrointestinal events in $3.0 \%$ (16), sepsis in $1.3 \%$ (7), mediastinitis in $1.3 \%$ (7), and disseminated intravascular coagulation in $0.9 \%$ (5). The median intensive care unit and hospital stays were 3 and 27 days, respectively. There were some complications related to the use of RAxA; motor palsy in 2 patients, muscle weakness in 8 patients, and numbness in 12 patients. Another 5 patients required repair of the RAxA for stenosis or thrombosed occlusion. However, except for 2 patients, most of these problems resolved. The midterm survival was $87.2 \%$ $\pm 1.7 \%$ at 3 years and $80.5 \% \pm 2.6 \%$ at 5 years.

\section{Discussion}

Despite advances in brain protection, arch surgery continues to be a challenge because of the high mortality and morbidity, including neurologic sequelae. ${ }^{1-5}$ To improve the outcome, we established the current SCP technique in 1999, which is physiologic and has a longer cerebral safety margin. This allows unhurried and secure arch surgery compared with the earlier retrograde cerebral perfusion. ${ }^{6-8}$ Subsequently, the outcome was satisfactory with a low early mortality of $4.0 \%$ and low incidence of permanent or temporary neurologic dysfunction of $2.9 \%$ or $9.9 \%$, even though high-risk emergency surgeries were involved.

However, during SCP, the risk of cerebral embolism associated with arch-vessel cannulation remains and may even increase the incidence of stroke. ${ }^{4,5}$ In arch surgery, other embolic phenomena may occur as the result of 1) cannulation or clamping of the diseased aorta and arteries, 2) a high-velocity jet caused by CPB via the ascending aorta across the aneurysm, 3) retrograde femoral perfusion through the diseased aorta, 4) external manipulation of the aorta and arch vessels, or 5) dislodgement of atheroma or clot inside the aorta. ${ }^{9}$ To overcome these problems, we used an alternative perfusion pathway using the distal segment of RAxA for both CPB and SCP. ${ }^{6-8}$ This part of the RAxA, which has less atherosclerosis or extension of aortic dissection, can easily be exposed and cannulated. In regard to AxA perfusion, there have been numerous reports on its routine or alternative use for $\mathrm{CPB}$ in cardiac surgery or for $\mathrm{CPB}$ and $\mathrm{SCP}$ in aortic surgery. ${ }^{9-20}$ These reports also advocated some advantages: less likelihood of stroke from embolic material, less likelihood of malperfusion with aortic dissection, less disruption of atheroma or calcified plaques, and the ability of administration of SCP. ${ }^{20}$ However, the cannulation site and techniques differ from ours, and the number of patients evaluated was smaller. In all, a proximal segment of the AxA below the clavicle (infraclavicular segment) is used, where larger-sized cannulae of $20 \mathrm{~F}$ to $26 \mathrm{~F}$ in size are accepted. However, the exposure was more time-consuming. ${ }^{9,11,13-15,18,20}$ For an emergency operation, our technique is more advantageous. For example, in acute dissection, 3 surgeons can start 3 different procedures without any interruptions, namely, RAxA exposure in the axilla, median sternotomy, and femoral artery exposure. In some, aortic dissection may extend down to the infraclavicular $\mathrm{AxA},{ }^{20}$ although it is rarely encountered on the distal segment. Furthermore, there is a potential risk of the right common carotid artery occlusion by an overly deep 
TABLE 3. Risk factors for permanent neurologic dysfunction determined by univariate analysis

\begin{tabular}{lccc}
\hline \multicolumn{1}{c}{ Variable } & $\boldsymbol{P}$ & OR & \multicolumn{1}{c}{$\mathbf{9 5 \%} \mathbf{~ C l}$} \\
\hline Age (y) & .082 & 1.06 & $0.99-1.14$ \\
Female gender & .007 & 4.51 & $1.52-13.42$ \\
Nondissecting aneurysm & .854 & 0.90 & $0.30-2.69$ \\
Emergency surgery & .070 & 2.60 & $0.92-7.31$ \\
Acute dissection & .507 & 1.48 & $0.46-4.76$ \\
Ruptured nondissecting & .062 & 4.43 & $0.93-21.3$ \\
$\quad$ aneurysm & & & \\
Arch-vessel malperfusion & .003 & 12.87 & $2.37-69.94$ \\
$\quad$ caused by acute dissection & & & \\
Atheromatous ascending & $<.0001$ & 104.72 & $29.40-372.90$ \\
$\quad$ aortic arch & & & \\
Chronic renal failure & .039 & 3.49 & $1.07-11.37$ \\
History of cerebrovascular & .436 & 0.55 & $0.12-2.48$ \\
$\quad$ event & & & \\
Carotid artery disease & .678 & 1.38 & $0.30-6.28$ \\
Intracranial artery disease & .188 & 2.40 & $0.65-8.79$ \\
Total arch replacement & .241 & 3.39 & $0.44-26.1$ \\
SCP (h) & .144 & 1.46 & $0.88-2.43$ \\
Open distal anastomosis & .261 & 2.23 & $0.55-9.08$ \\
$\quad$ with HCA (h) & & & \\
Deep hypothermia (20 $\left.{ }^{\circ} \mathrm{C}-22^{\circ} \mathrm{C}\right)$ & .191 & 2.01 & $0.71-5.74$ \\
\hline OR Odds & & & \\
\hline
\end{tabular}

$O R$, Odds ratio; $C l$, confidence interval; $S C P$, selective cerebral perfusion; $H C A$, hypothermic circulatory arrest.

cannula insertion. ${ }^{13}$ In regard to the AxA perfusion technique, some authors performed direct cannulation of a straight ${ }^{9,11,14,15,18,20}$ or right-angle cannula ${ }^{13}$ for easy and quick CPB establishment, whereas others preferred a sidegraft anastomotic technique to obtain sufficient $\mathrm{CPB}$ flow. ${ }^{10,12,14-16,20}$ For small patients, the side-graft technique is more advantageous, and it has been widely used because of less neurovascular complications. ${ }^{9,10,14,16}$ However, the side-graft procedure is more time-consuming and technically demanding. Bleeding from the anastomosis during the perfusion can become a nuisance. We therefore prefer simple and easy direct cannulation into the distal RAxA. It is the shortcomings of our technique that the distal RAxA is too small to accept larger-size cannulae. Therefore, additional (double) cannulation via the femoral artery or the ascending aorta is necessary for CPB. In the early series, femoral perfusion was routinely used. ${ }^{6}$ In this combination, the downstream flow via the RAxA can compete with the retrograde femoral perfusion flow in the descending aorta, which may prevent the potential risk of cerebral emboli. ${ }^{9,10,20}$ In acute dissection, this RAxA perfusion can prevent the collapse of the true channel in the proximal site. ${ }^{17}$ On the other hand, retrograde femoral perfusion not only allows the flushing out of debris in the descending aorta but also serves to check for bleeding from the key distal anastomosis. Moreover, perfusion of the spinal cord and visceral organs is possible through balloon occlusion of the descending aorta.
In the later series, in the absence of atherosclerotic change, ascending aorta cannulation yielding antegrade systemic CPB flow became our first choice. ${ }^{7,8}$ The proximal to mid-ascending aorta, away from the aneurysm, is generally safe. This strategy allowed us to avoid some drawbacks of femoral perfusion, including proximal emboli or retrograde dissection. Even in addition to the ascending perfusion, we still use the RAxA perfusion, because the switch from CPB perfusion to SCP is easy with no discontinuity by clamping the innominate artery, although in the standard SCP there remains by necessity a short period of circulatory arrest during insertion of the cannulae. With our technique, cannulationinduced emboli of the innominate artery or its new dissection can be avoided. Malposition of the SCP catheter in the innominate artery is not a rare event. ${ }^{21}$ With the innominate artery cannulated, the presence of dissection or severe atherosclerotic changes would make the anastomosis more difficult. Under the reliable SCP with RAxA perfusion, we have therefore been able to increase the bladder and nasopharyngeal temperature to $28^{\circ} \mathrm{C}$. If the ascending aorta is atherosclerotic, however, the femoral artery is still chosen for CPB. Femoral perfusion is added for patients presenting some difficulties with the distal anastomosis for severe atheromatous changes: to the combination of the RAxA and ascending perfusion, to perfuse the spinal cord and the visceral organs, or to flush out atheromatous debris.

In another setting, 5 patients required re-sternotomy surgery after the previous ascending aorta or arch surgery. There was a risk of aneurysmal rupture or graft injury at the re-sternotomy, even under femoro-femoral partial CPB, because the graft or enlarged aneurysm was attached to the sternum. We initiated CPB under RAxA and femoral perfusion and cooled them down. The sternum was reopened, immediately after the induction of deep hypothermia circulatory arrest, and brain protection was smoothly attained through SCP, which was easily established by just clamping the arch vessels under the RAxA perfusion.

The multivariate analysis demonstrated that chronic renal failure, ruptured nondissecting aneurysm, and prolonged surgery were the independent determinants for early mortality. All of these have been pointed out as risk factors. Svensson and colleagues ${ }^{20}$ and Kazui and colleagues ${ }^{22}$ also reported chronic renal failure as a risk factor for mortality. In general, patients with chronic renal failure tend to have severe atherosclerosis or calcification of the aorta and arteries. ${ }^{23}$ Some of these patients also have diabetic nephropathy. Sepsis or mediastinitis tends to develop in patients during postoperative hemodialysis. Surgery then involves a potentially higher risk. In regard to permanent neurologic dysfunction, archvessel malperfusion with acute dissection and rich atheroma in the ascending aorta and arch were significant independent predictors, associated with female gender and chronic renal failure. Statistically, a history of cerebrovascular event and carotid/intracranial artery disease were not risk factors. This 
finding was expected. The majority of permanent neurologic dysfunctions are considered to be caused by an embolism resulting from atheroma or clot, ${ }^{24}$ not cerebral hypoperfusion. Furthermore, in the cases with preoperative cerebral hypoperfusion caused by carotid or intracranial artery lesions, we modified our strategy to include a higher CPB perfusion pressure $(>60 \mathrm{~mm} \mathrm{Hg})$, deeper hypothermia $\left(20^{\circ} \mathrm{C}-22^{\circ} \mathrm{C}\right)$, and higher SCP flow rates by $20 \%$. These refinements seemed to yield good outcomes empirically, avoiding critical cerebral hypoperfusion. On the other hand, adequate brain protection is still controversial for patients with severe atheromatous lesions in the arch and arch vessels. In our practice, 11 high-risk patients with an atheromatous aorta had permanent neurologic dysfunction, despite the SCP with RAxA perfusion aiming at avoiding stroke. SCP requiring archvessel cannulation may result in cerebral embolism. ${ }^{4,5}$ Our strategy based on RAxA perfusion allows us to avoid cannulation, at least, of the innominate artery, which sometimes exhibits atheromatous changes or dissection. The left common carotid artery is less atheromatous in most, making its cannulation safe. The left subclavian artery often presents the most severe atheromatous changes, and cannulation is sometimes dangerous. Its cannulation must be carefully performed, removing some atheromatous parts, or patients should be cooled down to less than $22^{\circ} \mathrm{C}$ leaving the left subclavian artery uncannulated. In any case, even under RAxA perfusion, it is difficult to completely avoid cerebral emboli, particularly for high-risk patients with rich atheroma in the ascending aorta and arch, including the arch vessels. It is speculated that under RAxA perfusion, its high-velocity jet streaming retrogradely into the innominate artery might cause dislodgement of atheroma in the minor curvature of the arch, resulting in distal embolism. With a single inflow site via the AxA for $\mathrm{CPB}$, as described in the other reports, ${ }^{9-19}$ a higher-velocity jet is produced, which might adversely increase the risk of distal emboli. There is no way to completely avoid such cerebral emboli in patients with rich atheroma in the aorta, although its incidence would be reduced by our techniques. Our recommendation is to assess the ascending aorta and arch for atherosclerotic changes by epiaortic ultrasound imaging. In addition, arterial cannulation should be carefully performed with minimum manipulation of the aorta and arch vessels.

Cannulation into the distal RAxA was achieved in the overwhelming majority of patients $(97.4 \%)$. However, during the same interval, attempted RAxA cannulation was abandoned in 14 patients (2.6\%), who were excluded from this study. The cannulation was difficult because of the small size of the artery or the presence of stenosis. Thus, in these patients, the inflow site for CPB was shifted to the ascending aorta or femoral artery. For SCP, the innominate artery was also cannulated. ${ }^{4,5}$ In this subset, 1 patient $(7.1 \%)$ with an arch rupture associated with acute dissection died of low cardiac output, and 2 patients (14.3\%) had permanent neurologic dysfunction. There were some local complications related to the RAxA perfusion, such as vascular and nerve injuries in $5.6 \%$ of patients. Two patients also had left hand weakness. We think that some nerve injuries might be due to nerve compression caused by wide opening of the sternum for the distal anastomosis. At any rate, the incidence of complications was higher than in other reports describing the use of an infraclavicular AxA. ${ }^{9-20}$ The key to avoid these complications is gentle dissection and manipulation, while avoiding unnecessary traction of the brachial plexus. The RAxA is sometimes fragile and traumatized in younger patients and patients with aortic dissection or Marfan syndrome. For these patients, exposure and cannulation should be done carefully.

There are some limitations in this study. The logistic regression analyses were limited by the small number of events. This is a retrospective study in a single patient group who underwent aortic arch surgery with SCP through RAxA perfusion. To demonstrate the absolute (not theoretic) value of the RAxA perfusion, a multicenter prospective study is necessary.

\section{Conclusions}

RAxA perfusion in the axilla is an advantageous adjunct for $\mathrm{CPB}$ and $\mathrm{SCP}$ in arch surgery.

The authors thank Akiko Kada, biostatistician, for professional supervision on the statistical analysis.

\section{References}

1. Ueda Y, Miki S, Okita Y, Tahata T, Ogino H, Sakai T, et al. Protective effect of continuous retrograde cerebral perfusion on the brain during deep hypothermic systemic circulatory arrest. J Cardiac Surg. 1994;9: 584-95.

2. Coselli JS, LeMaire SA. Experience with retrograde cerebral perfusion during proximal aortic surgery in 290 patients. J Card Surg. 1997; 12(Suppl):322-5.

3. Okita Y, Takamoto S, Ando M, Morota T, Matsukawa R, Kawashima Y. Mortality and cerebral outcome in patients who underwent aortic arch operations using deep hypothermic circulatory arrest with retrograde cerebral perfusion: no relation of early death, stroke, and delirium to the duration of circulatory arrest. J Thorac Cardiovasc Surg. 1998;115: 129-38.

4. Bachet J, Guilmet D, Goudot B, Dreyfus GD, Delentdecker P, Brodaty D, et al. Antegrade cerebral perfusion in operations on the proximal thoracic aorta. Ann Thorac Surg. 1999;67:1874-8.

5. Kazui T, Washiyama N, Muhammad BA, Terada H, Yamashita K, Takinami M. Improved results of atherosclerotic arch aneurysm operations with a refined technique. J Thorac Cardiovasc Surg. 2001;121: 491-9.

6. Numata S, Ogino H, Sasaki H, Hanafusa Y, Ando M, Kitamura S, et al. Total arch replacement using antegrade selective cerebral perfusion with right axillary artery perfusion. Eur J Cardiothorac Surg. 2003;23:771-5.

7. Ogino H, Ando M, Sasaki H, Minatoya K. Total arch replacement using a stepwise distal anastomosis for arch aneurysms with distal extension. Eur J Cardiothorac Surg. 2006;29:255-7.

8. Minatoya K, Ogino H, Matsuda H, Sasaki H, Yagihara T, Kitamura S. Surgical management of distal arch aneurysm: another approach with improved results. Ann Thorac Surg. 2006;81:1353-7.

9. Sabik JF, Lytle BW, McCarthy PM, Cosgrove DM. Axillary artery: an alternative site of arterial cannulation for patients with extensive aortic 
and peripheral vascular disease. J Thorac Cardiovasc Surg. 1995;109: 885-91.

10. Baribeau YR, Westbrook BM, Charlesworth DC, Maloney CT. Arterial inflow via an Axillary artery graft for the severely atheromatous aorta. Ann Thorac Surg. 1998;66:33-7.

11. Neri E, Massetti M, Capannini G, Carone E, Tucci E, Diciolla F, et al. Axillary artery cannulation in type A aortic dissection operations. $J$ Thorac Cardiovasc Surg. 1999;118:324-9.

12. Sabik JF, Nemeh H, Lytle BW, Blackstone EH, Gillinov AM, Cosgrove DM, et al. Cannulation of the axillary artery with a side graft reduces morbidity. Ann Thorac Surg. 2004;77:1315-20.

13. Strauch JT, Spielvogel D, Lauten A, Lansman SL, McMurtry K, Griepp RB, et al. Axillary artery cannulation: routine use in ascending aorta and aortic arch replacement. Ann Thorac Surg. 2004;78:103-8.

14. Schachner T, Nagiller J, Zimmer A, Laufer G, Bonatti J. Technical problems and complications of axillary artery cannulation. Eur J Cardiothorac Surg. 2005;27:634-7.

15. Moizumi Y, Motoyoshi N, Sakuma K, Yoshida S. Axillary artery cannulation improves operative results for acute type A aortic dissection. Ann Thorac Surg. 2005;80:77-83.

16. Budde JM, Serna DL Jr, Osborne SC, Steele MA, Chen EP. Axillary cannulation for proximal aortic surgery is as safe in the emergent setting as in elective cases. Ann Thorac Surg. 2006;82:2154-60.

17. Orihashi K, Sueda T, Okada K, Imai K. Detection and monitoring of complications associated with femoral or axillary arterial cannulation for surgical repair of aortic dissection. J Cardiothorac Vasc Anesth. 2006;20:20-5

18. Panos A, Murith N, Bednarkiewicz M, Khatchatourov G. Axillary cerebral perfusion for arch surgery in acute type A dissection under moderate hypothermia. Eur J Cardiothorac Surg. 2006;29:1036-40.

19. Gulbins H, Pritisanac A, Ennker J. Axillary versus femoral cannulation for aortic surgery: enough evidence for a general recommendation? Ann Thorac Surg. 2007;83:1219-24.

20. Svensson LG, Blackstone EH, Rajeswaran J, Sabik JF 3rd, Lytle BW, Cosgrove DM, et al. Does the arterial cannulation site for circulatory arrest influence stroke risk? Ann Thorac Surg. 2004, 78:1274-84.

21. Orihashi K, Sueda T, Okada K, Imai K. Malposition of selective cerebral perfusion catheter is not a rare event. Eur J Cardiothorac Surg. 2005;27: 644-8.

22. Kazui T, Washiyama N, Muhammad BA, et al. Total arch replacement using aortic arch branched grafts with the aid of antegrade selective cerebral perfusion. Ann Thorac Surg. 2000;70:3-8

23. Hagl C, Galla JD, Spielvogel D, Bodian C, Lansman SL, Griepp RB, et al. Diabetes and evidence of atherosclerosis are major risk factors for adverse outcome after elective thoracic aortic surgery. J Thorac Cardiovasc Surg. 2003;126:1005-12.

24. Strauch JT, Spielvogel D, Lauten A, Galla JD, Lansman SL, Griepp RB, et al. Technical advances in total arch aortic replacement. Ann Thorac Surg. 2004;77:581-90.

\section{Discussion}

Dr Joseph Coselli (Houston, Tex). Congratulations on an excellent presentation. You report to us an incremental study regarding the Osaka experience with selective cerebral perfusion using axillary artery cannulation. Your approach is unusual in that you cannulate the distal axillary artery using an axillary artery incision and a small cannula, usually $10 \mathrm{~F}$ to $16 \mathrm{~F}$. Because of this, you also cannulate either the ascending aorta or the femoral artery to achieve adequate inflow. Your results are outstanding, with an operation mortality of $4 \%$ and a permanent neurologic deficit of $3 \%$ and no significant difference between elective and emergency operations, albeit with less than $8 \%$ of patients undergoing reoperation.

As your title suggests, you've evolved your strategy over a number of years with variations in such things as temperature and cannulation techniques. Because your results have been excellent apparently all along, it is not exactly clear to me as to what the motivation for the incremental alteration in your techniques has been.

Were there any differences in the outcomes from a neurologic, renal bleeding standpoint from the 4 different groups with regard to target temperatures that you have alluded to? For which patients, if any, do you continue to use deep hypothermic circulatory arrest?

You focus on bladder temperature. Knowing the limitations of bladder temperature monitoring, why do you not also monitor temperature in an area more accurately reflecting brain temperature, for example, the nasopharyngeal?

You recommend routine evaluation of cerebral circulation to help guide your perfusion strategy. One fourth of your patients had emergency procedures. What proportion of these patients had the benefit of preoperative imaging and how did this, if any, alter your technique? And if you do not have this preoperative imaging, exactly what perfusion techniques do you suggest?

Finally, rewarming strategy is also an important aspect of neuroprotection. What is your current rewarming approach? Do you use bladder temperature for this as well? What ultimate temperature do you target in your rewarming process? If you could, just mention to us your $\mathrm{pH}$ strategy.

Dr Ogino. As you know, in the past, we used retrograde cerebral perfusion with profound hypothermia in arch surgery. However, because the cerebral safety margin was limited and the incidence of postoperative temporary neurologic dysfunction was higher, our brain protection technique was shifted to selective antegrade cerebral perfusion in 2000 .

At the moment, as I mentioned, the routine temperature is $28^{\circ} \mathrm{C}$, regardless of aortic pathology. However, for high-risk patients with cerebral ischemia or renal dysfunction, we still use deep hypothermia at approximately $20^{\circ} \mathrm{C}$ to $22^{\circ} \mathrm{C}$ for cerebral or renal safety. In terms of bleeding or hemostasis, we are currently looking at the difference by a randomized control study between deep and moderate hypothermia in arch surgery. Our impression is that the amount of bleeding is less in the patient group with moderate hypothermia.

In regard to the temperature, we monitored the nasopharyngeal and bladder temperatures. In this study, we focused more on the bladder temperature as the core temperature, because we had to pay attention to the safety of spinal cord and visceral organs under moderate hypothermia. Selective antegrade cerebral perfusion is physiologic and has been well established. Under these circumstances, we focused more on the bladder temperature than the nasopharyngeal temperature.

In regard to the next question about the preoperative examination of cerebral circulation, routinely, brain computed tomography scans or carotid ultrasound was performed to evaluate the cerebral circulation. With a positive sign of ischemia in these examinations, magnetic resonance imaging or single photon emission computed tomography followed with the consultation of neurophysicians or neurosurgeon. With remarkable cerebral ischemia, we chose deep hypothermia and maintained the higher blood pressure during $\mathrm{CPB}$ and selective antegrade cerebral perfusion to avoid cerebral hypoperfusion. As you pointed out, one fourth of our patients were on emergency bases, such as acute dissection or ruptured nondissecting aneurysm. In this setting, preoperative evaluation was incomplete. 
So for those cases, we tended to choose a lower temperature because of less information on cerebral circulation. Exceptionally, for relatively young patients with acute dissection without cerebral malperfusion, moderate hypothermic surgery at $25^{\circ} \mathrm{C}$ to $28^{\circ} \mathrm{C}$ was performed because these patients unlikely had any atherosclerotic cerebrovascular diseases.
As you mentioned, the rewarming process is also important for brain protection. Slow rewarming to the nasopharyngeal temperature of approximately $30^{\circ} \mathrm{C}$ to $32^{\circ} \mathrm{C}$ was started after reconstruction of the left subclavian artery. Full rewarming was commenced after complete reconstruction of the arch vessels. In terms of $\mathrm{pH}$ strategy, we used alpha-stat strategy for cooling and rewarming. 